\title{
Finite ELEMENT SimUlation OF DAMAGE IN RC BEAMS
}

\author{
M. U. Hanif ${ }^{1}$, Z. Ibrahim ${ }^{1}$, K. Ghaedi ${ }^{1}$, A. Javanmardi ${ }^{1}$ and S. K. Rehman ${ }^{1}$ \\ ${ }^{1}$ Department of Civil Engineering, Faculty of Engineering, University of Malaya, 50603 Kuala Lumpur, Malaysia.
}

Date received: 17/03/2018, Date accepted: 20/04/2018

Corresponding author's email: zainah@um.edu.my, usmanhnf@gmail.com

\begin{abstract}
A concrete damage model has been incorporated in finite element code ABAQUS as concrete damaged plasticity model to examine the sensitivity of the damage, as ABAQUS has the model that is capable of stiffness degradation in cracking which is the basis of fracture mechanics. Nonlinear constitutive relationships for concrete and steel have been incorporated in the model. The static and dynamic response of the structure at 10 different damage levels is studied and the sensitivity of the damage model towards the presence of non-linearity has been discussed. The concrete damaged plasticity model is capable of predicting formation of cracks in concrete beams against any kind of loads, as the results match with the experimental results. It can be concluded that the concrete damaged plasticity is a versatile tool for modeling RC structures and careful choice of solution procedures for dynamic analysis can lead to accurate modeling of concrete using a few routine laboratory test results of the materials.
\end{abstract}

Copyright $\odot 2018$ UNIMAS Publisher. This is an open access article distributed under the Creative Commons Attribution-NonCommercial-ShareAlike 4.0 International License which permits unrestricted use, distribution, and reproduction in any medium, provided the original work is properly cited.

Keywords: finite element modeling; Reinforced concrete damage, structural health monitoring

\subsection{INTRODUCTION}

Concrete is a very unique material. It exhibits strength in compression and is weak in tension. The postpeak softening behavior in tension makes concrete a quasi-brittle material. Reinforced concrete is a composite in which concrete tackles the compression and the reinforcement cater for the tension. Concrete is a very popular construction material which provides serviceability, economy and durability better than other construction materials.

Modeling of reinforced concrete is a complex process. The detailed modeling may lead to accuracy but may make it computation intensive and vice versa. However, incorporating an accurate model in damage detection is the foundation of the SHM applications. Most of the damage detecting scenarios in the concrete assume the linear i.e. the structure is assumed to behave linearly after the damage. In contrast to this, the structures exhibit nonlinear behavior due to presence of microcracks. Most of the past research is based on linear damage detection methods. A comprehensive review of those methods can be found [1]. Vibration procedures are very popular due to the convenience in getting the response of the structure through only a few measurements. A brief review of vibration procedures can be found in [2].

The non-linear damage detection procedures are quite complicated, therefore engineering simplifications are usually taken into consideration to make the procedures more convenient. As concrete is a cohesive material, it doesn't show brittle or ductile response. Concrete shows softening behavior after the strength is reached, in compression as well in tension. So, the damage detection procedures incorporated successfully in manufacturing and industrial applications cannot be deployed in damage detection of concrete structures.

Recently it has been found that the damage in concrete structures can be detected by modeling the nonlinear behavior of cracked. The fictitious crack model offers the nonlinear post peak softening behavior, which is capable of reproducing the nonlinear behavior in concrete modeling. This has opened the possibilities of checking the capabilities of other non-linear models also in structural damage detection. The modal analysis is good indicator of damage, but due to environmental factors, they are found not much sensitive to damage in concrete structures $[1,3]$. 
A tensile constitutive relation [4] was used to model cracked concrete. The model is capable of representing the realistic crack behavior of concrete and was used recently for damage modeling RC beams [5]. The model is analytically precise in translating the experimental results but it has limited application in concrete modeling. This study is focused on whether the linear models, for example natural frequency degradation, are capable of reproducing the non-linear behavior in concrete modeling or not.

\subsection{CONSTITUTIVE RELATIONS}

The compressive model used in this study translates stress-strain behavior of concrete in agreement with most of the models [6]. The focus of this study will shift towards tensile concrete modelling, so a convenient compressive model is chosen for the ease of this study. Commercial finite element software ABAQUS was used for modeling RC beam. The model used for compressive strength of concrete is the concrete damage plasticity model (CDPM) [7]. The compressive constitutive relations [6] were incorporated in CDPM as:

$$
\frac{f}{f^{p}}=\frac{\beta\left(\frac{E}{E_{L}}\right)}{\beta-1+\left(\frac{\varepsilon}{e_{E}^{p}}\right)^{\beta}}
$$

Where,

$$
\beta=\frac{1}{1-\frac{f_{c}^{f}}{e_{c}^{f} e_{i e}}}
$$

$\mathrm{fc}=$ Compressive strength of concrete

$\mathrm{f}^{\prime} \mathrm{c}=$ concrete cylinder compressive strength at 28 days

$\varepsilon=$ the concrete strain

$\varepsilon^{\prime}{ }_{c}=$ strain at peak stress

$$
\begin{aligned}
& \varepsilon_{c}^{t}=\left(0.71 f_{e}^{\prime}+168\right) * 10^{-5} \\
& E_{\text {it }}=\left(\frac{24.92}{f_{\text {r }}^{v}}+0.92\right) * \frac{f_{c}^{\prime}}{\varepsilon_{c}^{\prime}}
\end{aligned}
$$

The concrete damage plasticity model was chosen in finite element software ABAQUS [7]. There are three built-in concrete models available namely Concrete Smeared Cracking, Concrete Damaged Plasticity and Cracking Model for Concrete in ABAQUS/Explicit, but the concrete damaged plasticity model has advantage of carrying out static and dynamic analysis of reinforced concrete members with bars embedded and has good convergence. The model includes tensile isotropic damage model which accounts for tensile cracking and the compressive crushing modes. Most importantly the model is also capable of stiffness degradation with irreversible damage that occurs during fracture process [8]. The response of concrete to uniaxial tension and compression is shown in Figures $1(a)$ and $1(b)$ respectively.

The damage parameters have been taken as a function of plastic strains, and they are zero representing undamaged material and one representing the total loss of strength [7]. 

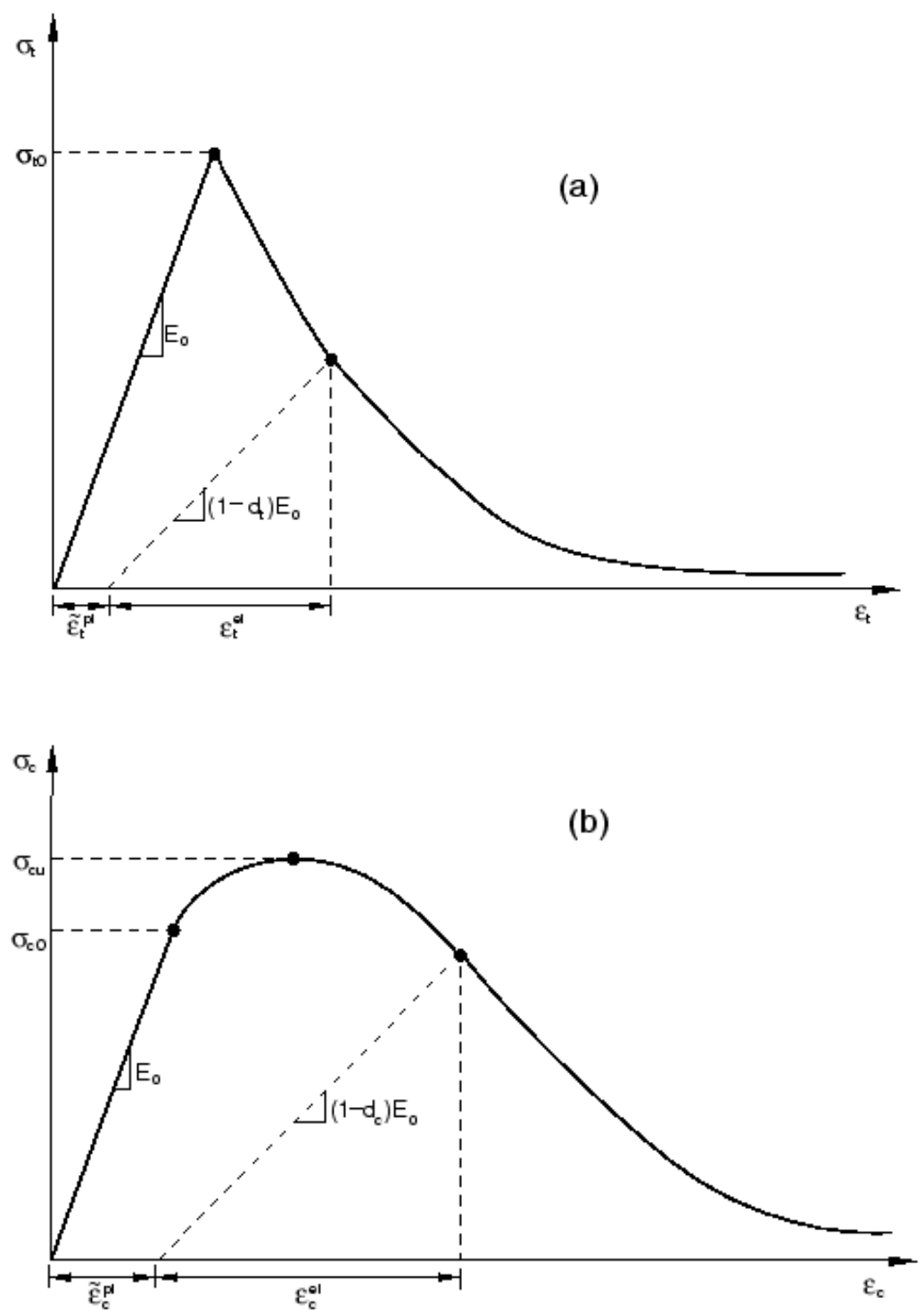

Figure 1 Response of concrete to uniaxial loading in (a) tension and (b) compression.

\subsection{FEM SIMULATION}

The reference test data were taken from another research, the specimens details and material designs were taken from Hamad et al. [5]. Some brief details of the material properties are given in Table 1 and Table 2. The model geometry is shown in Figure 3.

Table 1 Mechanical properties of concrete

\begin{tabular}{lllll}
\hline Density & fcu & Fct & Ec & $v$ \\
Tonne/mm & $M P a$ & $M P a$ & $M P a$ & \\
\hline $2.4 \mathrm{E}-9$ & 36.5 & 3.65 & 26957.85 & 0.15 \\
\hline
\end{tabular}

Table 2 Mechanical properties of steel reinforcement

\begin{tabular}{cccc}
\hline Bar type & $\begin{array}{c}\text { Diameter } \\
(\mathrm{mm})\end{array}$ & $\begin{array}{c}\text { Fy } \\
(\mathrm{MPa})\end{array}$ & $\begin{array}{c}\text { Es } \\
(\mathrm{MPa})\end{array}$ \\
\hline Plain Bars & 6 & 393.6 & 208.4 \\
Main Bars & 10 & 540.8 & 199.2 \\
\hline
\end{tabular}


The bond between concrete and reinforcing steel was kept a perfect bond i.e. the deformations in steel and concrete were the same at interface. It was achieved by using constraint as embedded region to embed steel in the concrete part. The support conditions were kept simply supported (vertical and horizontal restraint on nodes on left support and vertical restraint on the right support, see Figure 2). There was no accumulation of stresses at the supports and the fundamental modal frequency was in agreement with the reference model [5].

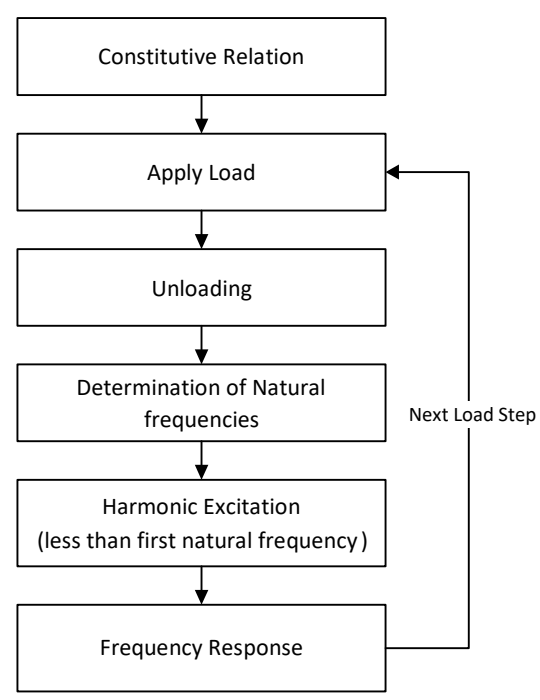

Figure 2 Flow chart for analyzing the concrete model

The static loading was applied in incremental manner. The maximum allowable load of the beam (43KN) was divided into 10 steps. The beam was loaded at each step, then unloaded to zero load and then the harmonic excitation was applied to check its response as shown in Figure 3.

For dynamic analysis, a harmonic excitation was applied to the beam after each static incremental loading. The natural frequency was determined by adding the frequency in stepping for linear perturbation procedure type. A linear perturbation step of the system provides the linear response of the system about the last non-linear step (base state) prior to the linear perturbation stem. The input harmonic signal (less than fundamental frequency) of $30 \mathrm{~Hz}$ was applied for a duration of 5 seconds. The vertical displacement response was recorded at the locations of the accelerometers in the experiment [5]. The average of response was used for fast Fourier transform. Raleigh damping was used for the model with damping ratio taken as 5 percent [9].

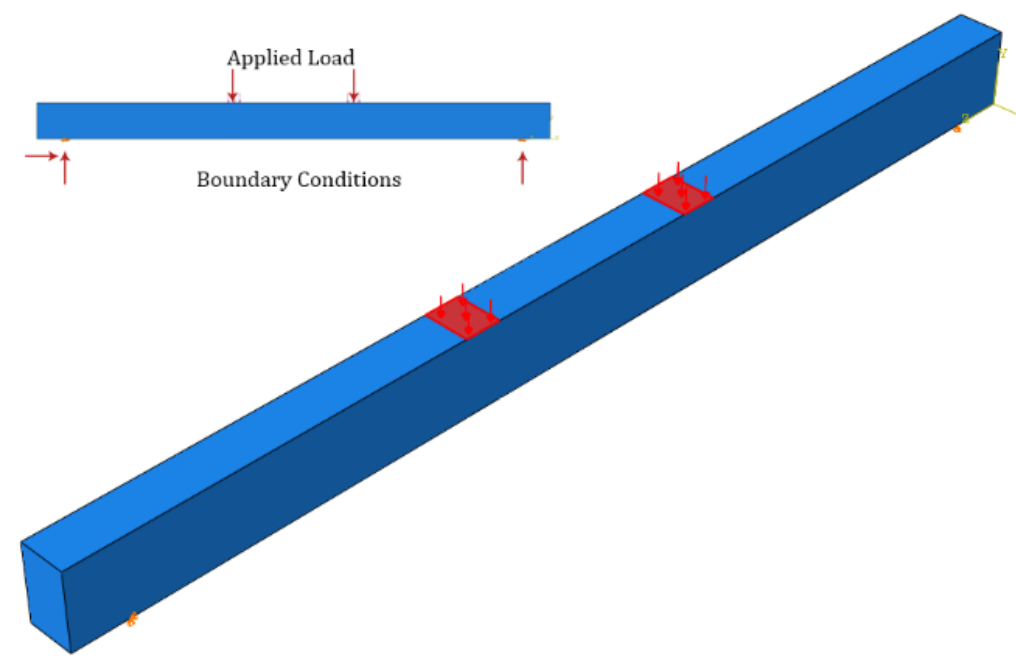

Figure 3 FE model of the beam 


\subsection{RESULTS AND DISCUSSION}

\subsection{STATIC RESPONSE}

The bond between concrete and steel reinforcement was made a perfect bond and the stresses in steel can be seen in Figure 4.

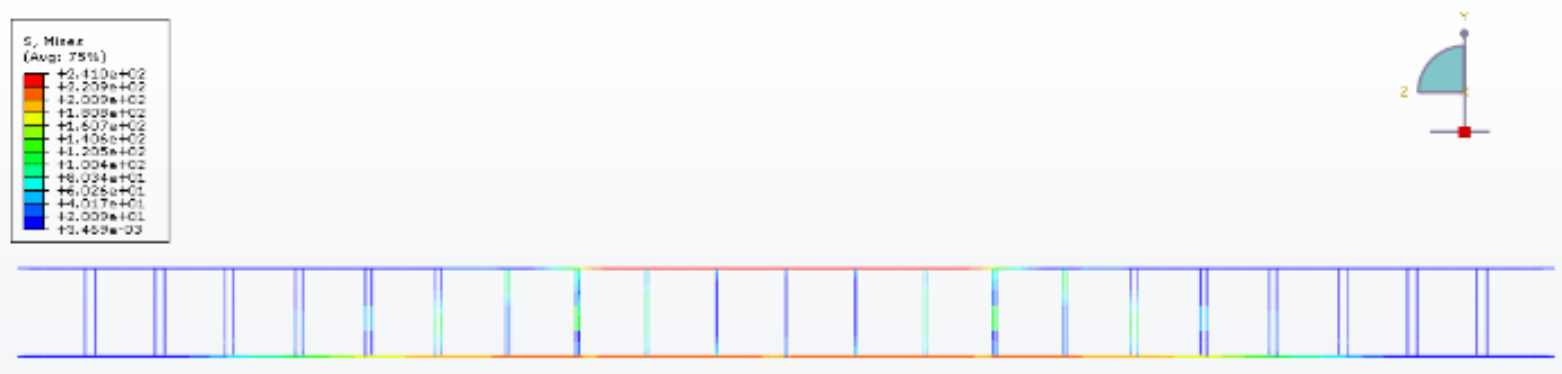

Figure 4 Mises stresses in reinforcement at 90\% damage level

The load deflection response is shown in Figure 5 for $60 \%$ of the maximum load. The response of the beam remains in elastic region for up to $30 \%$ load. The beam is capable of taking more loads but the modal frequencies start changing abruptly at maximum load. Self-weight also contributes to the deflection.

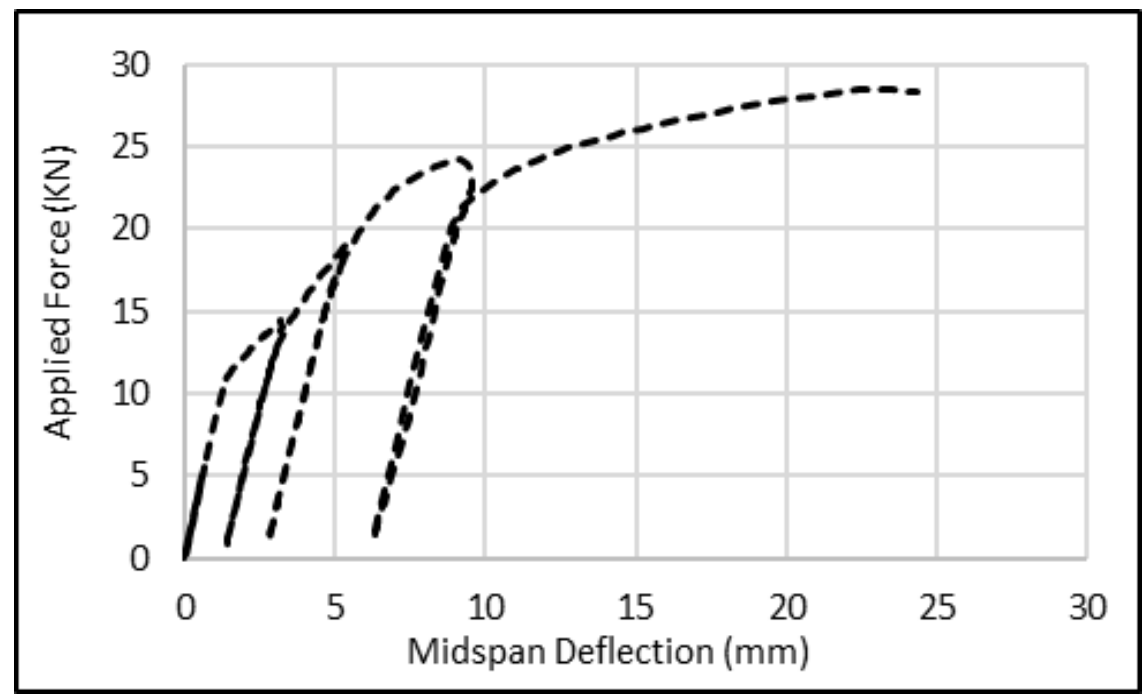

Figure 5 Load deflection behavior up to $60 \%$ load

\subsection{CRACKING PATTERN}

The cracks started forming at around $30 \%$ of the maximum load. The current model somewhat follows the similar constitutive model (fictitious crack model) which was experimentally proved previously [10]. The advantage of this model of beam is that it is capable of producing realistic crack formation. The flexural cracks in the shear span start getting inclined after 40 percent of the failure load. The crack pattern and its comparison with a recent flexural model sensitive to damage for the beam at $90 \%$ of failure load is demonstrated in Figure 6. The blue dashed lines in the figure represent the initiation of cracks in the reference beam. It shows close resemblance with the simulated crack formation. 


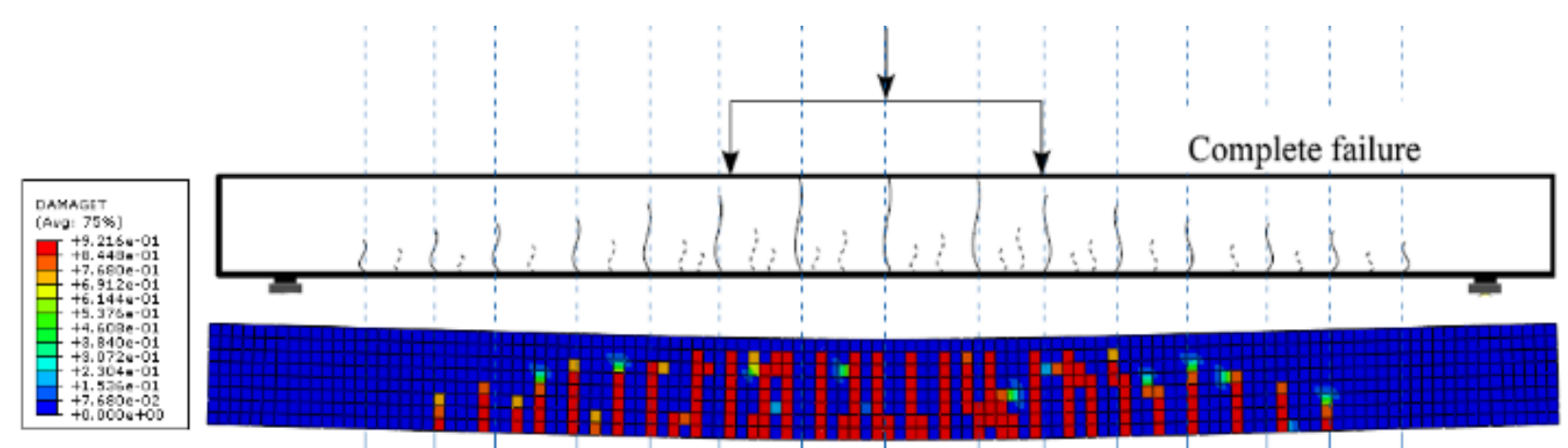

Figure 6 Crack formation comparison of simulated beam with another model [5]

\subsection{DYNAMIC RESPONSE}

The response of the beam was recorded against a harmonic excitation of $30 \mathrm{~Hz}$. The modal frequencies for first five bending modes were also recorded with the increase of damage load. The natural frequencies reduced with the increase of damage. The frequencies were normalized and their behaviour is shown in Figure 7. There was maximum of $25 \%$ of modal frequencies at higher modes. The natural frequencies remained constant for up to $30 \%$ of damage load because the response of the beam was in elastic zone.

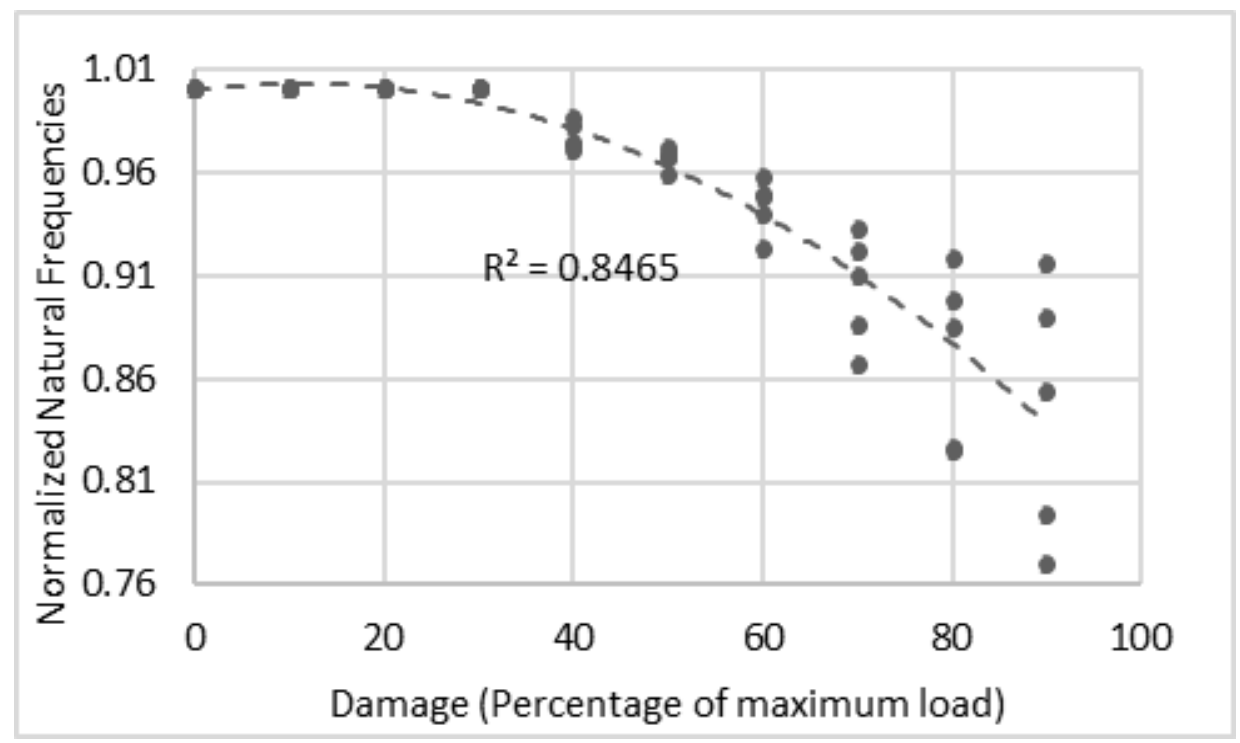

Figure 7 Reduction in modal frequencies with damage

Formation of super-harmonics is a popular method of detecting the presence of nonlinear behaviour. As the concrete cracks, the cracks should hinder concrete from vibrating in a perfect sinusoidal manner, and resultantly the super-harmonics should appear in the PSD [11,12]. The power spectral density of the present model was determined at every load interval, as shown in Figure 8. There was no formation of super-harmonics, which indicates that the modal dynamic approach is reproducing the nonlinear behavior through super-harmonics. The power spectrum density of the beam at peak load of $40 \%$ damage was also calculated, resulting in no super-harmonics. The response of the structure needs to be investigated by incorporating nonlinearity which has been observed previously $[13,14]$. A recent study by the authors [15] shows that the implicit dynamic analysis is capable of reproducing the nonlinear behavior. 


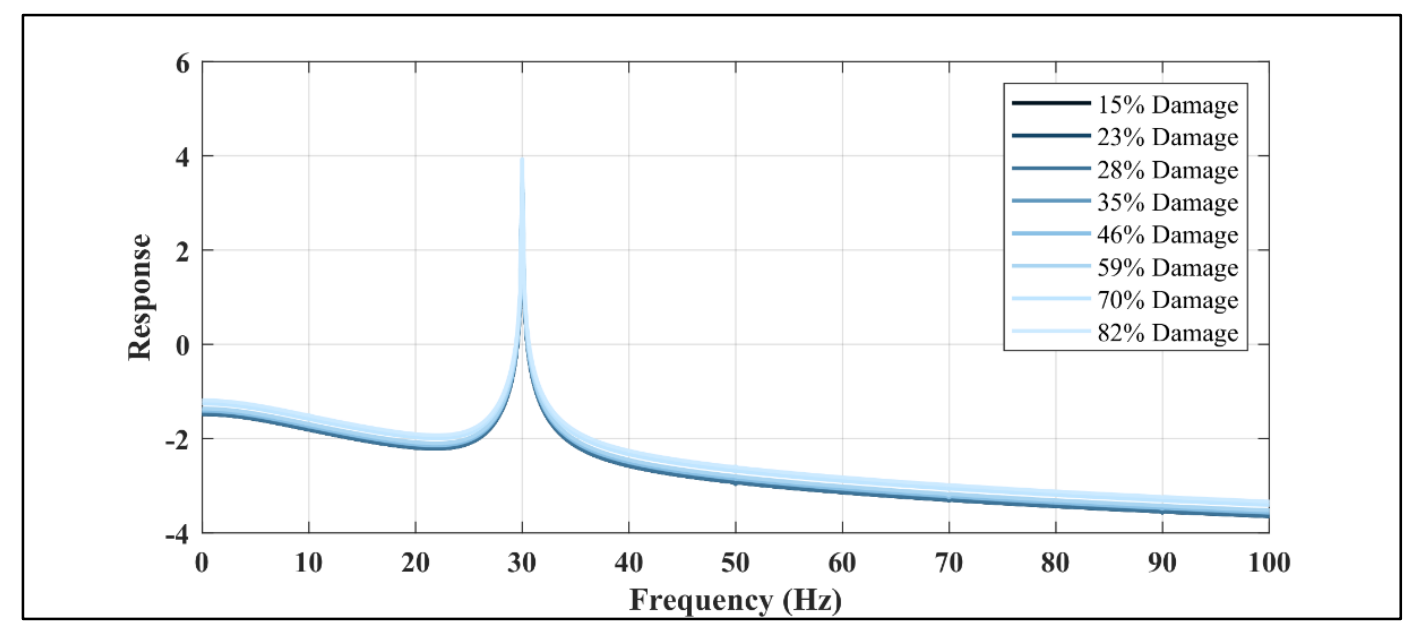

Figure 8 Nonlinear behavior not found in modal dynamic analysis

\subsection{CONCLUSIONS}

The commonly incorporated natural frequency determination procedure was incorporated in reproducing the nonlinear behavior through the formation of super-harmonics in cracked RC beam. The incremental damage was applied in identifying natural frequencies. At the same time a sinusoidal excitation was applied on the beam to observe nonlinear behavior using the modal dynamic procedure. Based on the above study, the following conclusions can be drawn:

1. The currently proposed simulation technique is an effort in assisting practicing engineers and consultants to use at-hand software packages to conveniently model the damage in existing structures.

2. Concrete damaged plasticity model is capable of predicting formation of cracks in concrete beams against any kind of loads, as the results match with the experimental results.

3. The concrete cracking can be reasonably represented by the built-in damage crack visualization variable 'dt'.

4. Currently the built-in concrete damaged plasticity model is not sensitive to damage using linear vibration techniques. But if using nonlinear dynamic analysis (for example dynamic implicit) the nonlinearity maybe induced and the damage can be detected based on the extent of non-linearity, thus detecting the damage based on current condition of the structure and not requiring the intactstate response data from the structure.

With all being said, the concrete damaged plasticity is a versatile tool for modeling RC structures and careful choice of solution procedures for dynamic analysis can lead to accurate modeling of concrete using a few routine laboratory test results of the materials.

\section{ACKNOWLEDGMENT}

The authors would like to acknowledge several research funds and support by the University of Malaya Research Grant (UMRG-Project No. RP004A-13AET), University of Malaya Postgraduate Research Fund (PPP-Project No. PG187-2014B) and Fundamental Research Grant Scheme, Ministry of Education, Malaysia (FRGS-Project No. FP004-2014B).

\section{REFERENCES}

[1] O. S. Salawu and C. Williams, "Review of full-scale dynamic testing of bridge structures," Eng. Struct., vol. 17, no. 2, pp. 113-121, Feb. 1995.

[2] S. W. Doebling, C. R. Farrar, M. B. Prime, and others, "A summary review of vibration-based damage identification methods," Shock Vib. Dig., vol. 30, no. 2, pp. 91-105, 1998. 
[3] O. Salawu and C. Williams, "Damage location using vibration mode shapes," Proc. 12th Int. ..., 1994.

[4] A. Hillerborg, "Application of the fictitious crack model to different types of materials," Int. J. Fract., vol. 51, no. 2, pp. 95-102, 1991.

[5] W. I. Hamad, J. S. Owen, and M. F. M. Hussein, "Modelling the degradation of vibration characteristics of reinforced concrete beams due to flexural damage," Struct. Control Heal. Monit., vol. 22, no. 6, pp. 939-967, Jun. 2015.

[6] D. J. Carreira and K.-H. Chu, "Stress-Strain Relationship for Plain Concrete in Compression," J. Proc., vol. 82, no. 6, pp. 797-804, Nov. 1985.

[7] A. Documentation, “ABAQUS Analysis User's Manual,” Mater. Other Plast. Model. Concr., 2010.

[8] J. Rodriguez Soler, F. J. Martinez Cutillas, and J. Marti Rodriguez, "Concrete constitutive model, calibration and applications," 2013 SIMULIA Community Conf., 2013.

[9] R. W. Clough and J. Penzien, "Dynamics of structures," 1975.

[10] B. L. Wahalathantri, D. P. Thambiratnam, T. H. T. Chan, and S. Fawzia, "A material model for flexural crack simulation in reinforced concrete elements using ABAQUS," in Proceedings of the First International Conference on Engineering, Designing and Developing the Built Environment for Sustainable Wellbeing, 2011, pp. $260-264$.

[11] S. A. Neild, P. D. McFadden, and M. S. Williams, "Damage Assessment in Concrete Beams Using Non-Linear Analysis of Vibration Measurements," Key Eng. Mater., vol. 245-246, pp. 557-564, Jul. 2003.

[12] W. I. Hamad, J. S. Owen, and M. F. M. Hussein, "A flexural crack model for damage detection in reinforced concrete structures,” J. Phys. Conf. Ser., vol. 305, no. 1, p. 012037, Jul. 2011.

[13] D. A. Hordijk, "Tensile and tensile fatigue behaviour of concrete; experiments, modelling and analyses," Heron, vol. 37, no. 1, 1992.

[14] W. I. Hamad, J. S. Owen, and M. F. M. Hussein, "An efficient approach of modelling the flexural cracking behaviour of un-notched plain concrete prisms subject to monotonic and cyclic loading," Eng. Struct., vol. 51, pp. 36-50, Jun. 2013.

[15] M.U. Hanif et al., "A new approach to estimate damage in concrete beams using non-linearity," Construction and Building Materials, Vol. 124: pp. 1081-1089, 2016. 